\title{
Erratum to: Virological and Clinical Characteristics of Hepatitis B Virus Genotype A
}

\author{
Kiyoaki Ito $^{1} \cdot$ Masashi Yoneda $^{1} \cdot$ Kazumasa Sakamoto $^{1} \cdot$ Masashi Mizokami $^{2}$
}

Published online: 25 July 2017

(C) Japanese Society of Gastroenterology 2017

\section{Erratum to: J Gastroenterol \\ DOI 10.1007/s00535-017-1367-5}

In the original publication of the article, Figure 1 was published incorrectly. The correct figure is given in this erratum.

The online version of the original article can be found under doi:10.1007/s00535-017-1367-5.

Kiyoaki Ito

kito@aichi-med-u.ac.jp

1 Department of Gastroenterology, Aichi Medical University School of Medicine, 1-1 Yazakokarimata, Nagakute, Aichi 480-1195, Japan

2 The Research Center for Hepatitis and Immunology, National Center for Global Health and Medicine, Ichikawa, Japan 
Geographic distribution

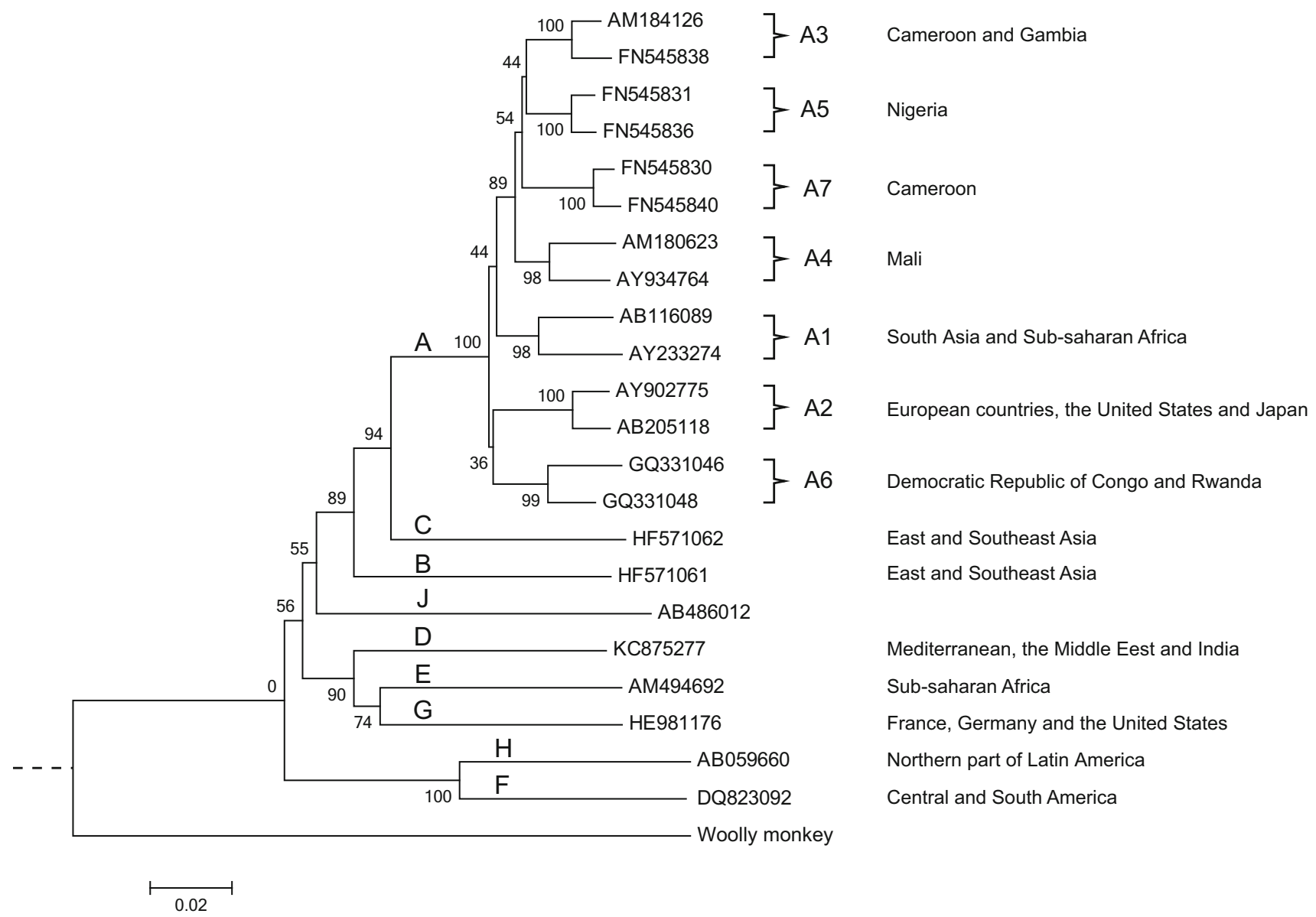

